\title{
Corrigendum to "Analyzing Critical Failures in a Production Process: Is Industrial IoT the Solution?"
}

\author{
Shafiq Ahmad $\mathbb{D}$, ${ }^{1}$ Ahmed Badwelan $\mathbb{D D}^{1}{ }^{1}$ Atef M. Ghaleb, ${ }^{1}$ Ammar Qamhan ${ }^{\mathbb{D}}{ }^{1}$ \\ Mohamed Sharaf, ${ }^{1}$ Moath Alatefi $\left(\mathbb{D},{ }^{1}\right.$ and Ammar Moohialdin ${ }^{(D)}{ }^{2}$ \\ ${ }^{1}$ King Saud University, College of Engineering, Department of Industrial Engineering, Riyadh 11421, Saudi Arabia \\ ${ }^{2}$ School of Civil Engineering and Built Environment, Science and Engineering Faculty, Queensland University of Technology, \\ Brisbane 4000, Australia \\ Correspondence should be addressed to Shafiq Ahmad; ashafiq@ksu.edu.sa
}

Received 10 April 2019; Accepted 18 April 2019; Published 30 October 2019

Copyright (c) 2019 Shafiq Ahmad et al. This is an open access article distributed under the Creative Commons Attribution License, which permits unrestricted use, distribution, and reproduction in any medium, provided the original work is properly cited.

In the article titled "Analyzing Critical Failures in a Production Process: Is Industrial IoT the Solution?" [1], Dr. Moath Alatefi and Dr. Ammar Moohialdin were missing from the authors' list.

Dr. Ammar Moohialdin conceived the idea, provided the data, and revised and commented on an earlier draft of the article. In addition, Dr. Moath Alatefi worked as a statistical consultant during the preparation and the revision of the article. The corrected authors' list is shown above.

The acknowledgments section to be as: "The authors extend their appreciation to the Deanship of Scientific Research at King Saud University for funding this work through research group no. (RG- 1438-089).”.

\section{References}

[1] S. Ahmad, A. Badwelan, A. M. Ghaleb, A. Qamhan, and M. Sharaf, "Analyzing Critical Failures in a Production Process: Is Industrial IoT the Solution?" Wireless Communications and Mobile Computing, vol. 2018, Article ID 6951318, 12 pages, 2018. 


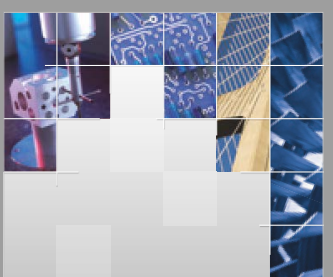

\section{Enfincering}
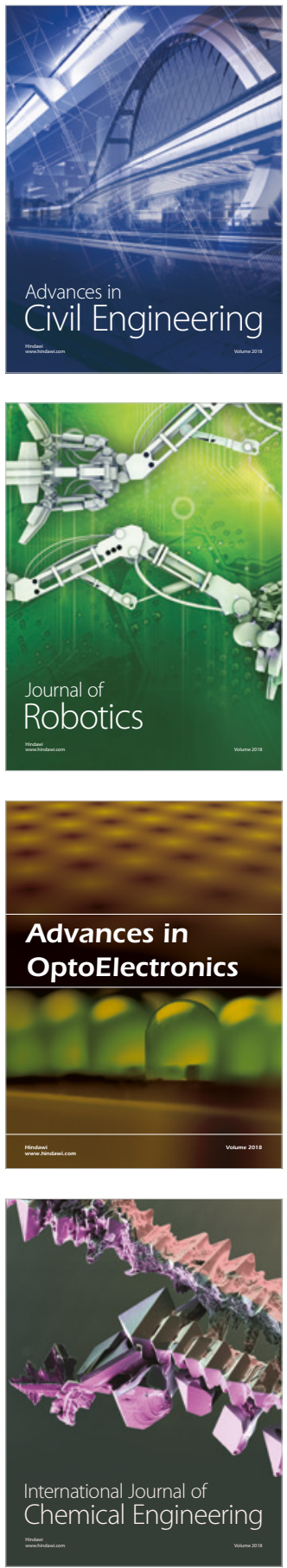

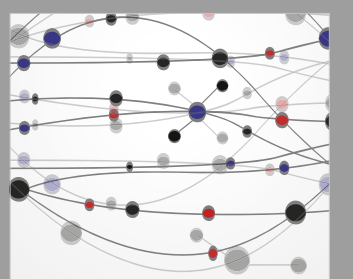

\section{Rotating \\ Machinery}

The Scientific World Journal

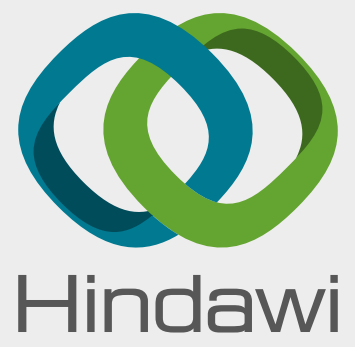

Submit your manuscripts at

www.hindawi.com
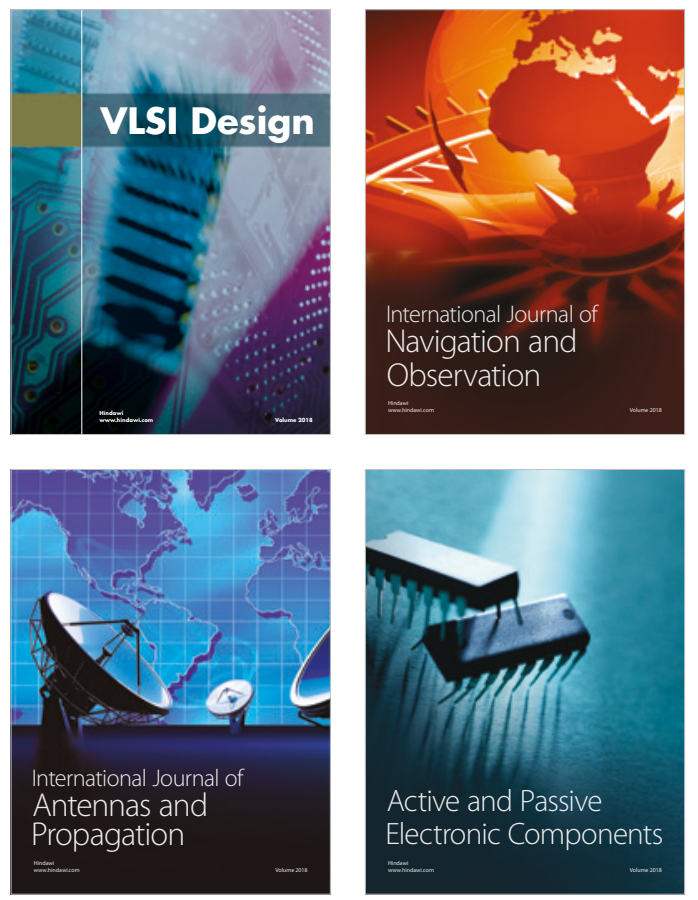
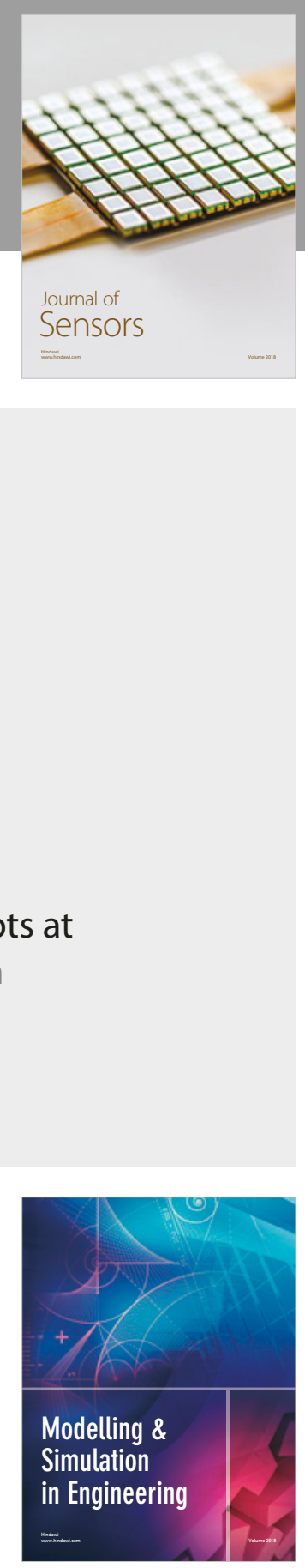

\section{Advances \\ Multimedia}
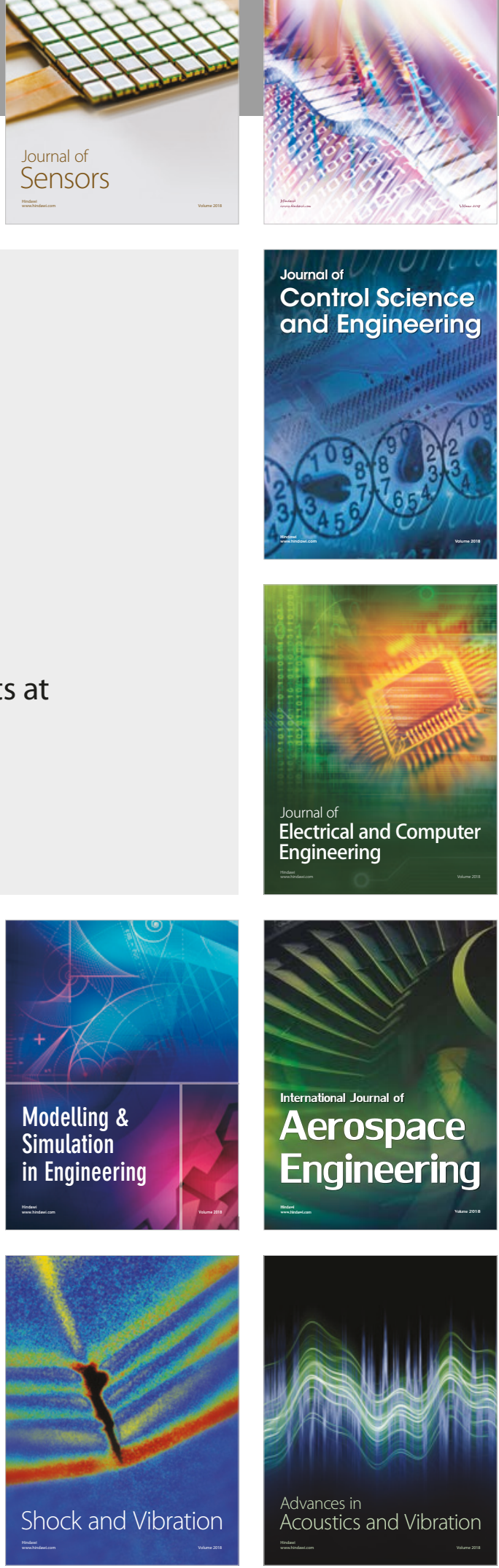